\title{
Geoinformatics based Valuation of Forest Landscape Dynamics in Central Western Ghats, India
}

\section{Ramachandra $\mathrm{TV}^{1^{*}}$ and Bharath $\mathbf{S}^{2}$}

${ }^{1}$ Energy and Wetlands Research Group, Centre for Ecological Sciences, Indian Institute of Science, Bangalore, India

${ }^{2}$ Energy and Wetlands Research Group, Center for Ecological Sciences [CES], Lab of Spatial Informatics, IIIT-H, Hyderabad, India

"Corresponding author: Ramachandra TV, Energy and Wetlands Research Group, Centre for Ecological Sciences, Indian Institute of Science, Bangalore, India, Tel: +91-80-2293-3099; E-mail: tvr@iisc.ac.in

Rec date: January 05, 2018; Acc date: January 29, 2018; Pub date: January 30, 2018

Copyright: @ 2018 Ramachandra TV, et al. This is an open-access article distributed under the terms of the Creative Commons Attribution License, which permits unrestricted use, distribution, and reproduction in any medium, provided the original author and source are credited.

\begin{abstract}
Landscape dynamics driven by land use land cover (LULC) changes due to anthropogenic activities altering the functional ability of an ecosystem has influenced the ecology, biodiversity, hydrology and people's sustainable livelihood. Forest landscape dynamics have been quantified using spatial data acquired through space borne sensors along with collateral data. Vegetation cover assessment of Central Western Ghats shows the decline of vegetation from $92.87 \%$ (1973) to $80.42 \%$ (2016). Land use analyses reveal the trend of deforestation, evident from the reduction of evergreen-semi evergreen forest cover from $67.73 \%$ (1973) to $29.5 \%$ (2016). The spatial patterns of diverse landscape have been assessed through spatial metrics and categorical principal component analysis, reveal a transition of intact forested landscape (1973) to fragmented landscape. The analysis has provided insights to formulate appropriate policies to mitigate forest changes in the region to safeguard water and food security apart from livelihood of the local people for sustainable development.
\end{abstract}

Keywords: Landscape dynamics; Forest fragmentation; Land use; Land cover changes; NDVI; CATPCA; Spatial metrics

\section{Research Highlights}

- The objective of the current study is to assess the spatial patterns of landscape changes in the forested district (Uttara Kannada district) of Central Western Ghats in Karnataka, India.

- Vegetation cover assessment shows the decline of vegetation from $92.87 \%$ (1973) to $80.42 \%$ (2016).

- Land use analyses reveal the trend of intensive deforestation, evident from the reduction of evergreen-semi evergreen forest cover from $67.73 \%$ (1973) to $29.5 \%$ (2016).

- The present communication is aimed to understand the role of landscape metrics to define relationship between land use and landscape structure.

- The spatial patterns of diverse landscape have been assessed through spatial metrics and categorical principal component analysis; reveal a transition of intact forested landscape (1973) to fragmented landscape with the increased patchiness (2016).

- This analysis provided insights to formulate appropriate policies to mitigate forest changes and devising appropriate effective management and decision making towards the sustainable development of the region.

\section{Introduction}

Landscape consists of heterogeneous biophysical elements with dynamic interactions [1] that ensures the sustainability of natural resources. The complex interactions among ecological, economic, social and cultural entities, which depend on the structure of the landscape play a decisive role in the respective ecosystem's functions (cycling of water and nutrients, bio-geo-chemical cycles, etc.). This necessitates understanding of landscape structure (size, shape, and configuration) and constituent's spatial patterns (linear, regular and aggregated) through land use land cover [LULC] analysis. Land cover [LC] relates to the discernible Earth surface expressions, such as vegetation or non-vegetation (soil, water or anthropogenic features) indicating the extent of Earth's physical state in terms of the natural environment [2-4]. Land use [LU] provides human uses of the landscape, e.g., habitations, agricultural lands, etc. Accelerated LULC changes in the recent decades by the enhanced anthropogenic activities have been playing a major role in altering climate and biogeochemistry patterns at global as well as at regional scales [5,6]. Burgeoning population and increased consumption levels has led to the conversion of about 40 percent of Earth's surface to cropland, etc. at the expense of forests and natural grasslands [7]. Uncontrolled LULC changes affect health of ecosystem [8,9] and determine the vulnerability of humans, locations due to climatic, economic or socio-political perturbations [10-12]. Temporal LULC information is vital for elucidating landscape dynamics, essential for regional planning and sustainable management of natural resources $[7,13]$.

LULC information has become prime prerequisites to overcome the problems of haphazard, uncontrolled development, quantifying deteriorating environmental quality through time. Monitoring and management of natural resources requires accurate, timely, synoptic and repetitive coverage over large area across various spatial scales. Remote sensing (RS) data along with Geographic Information System (GIS) and GPS (Global positioning system) help in inventorying, mapping and monitoring of earth resources for an effective and sustainable landscape management $[3,14,15]$ with better spectral (Multi Spectral data, Hyper spectral data, etc.) and spatial resolution data (Low, Medium, High). Landscape metrics also known as spatial metrics or spatial pattern statistics are universally well acknowledged to perceive shape and pattern of landscape heterogeneity of different patches at local scale [16-21]. Cluster analysis helps in grouping the 
components to compute the universality, strength, and consistency of the landscape structure components [22,23]. Categorical Principal Component Analysis (CATPCA) is an effective method to reduce the number of dimensions in the data while retaining variability. Standard Principal Components Analysis (PCA) assumes linear relationships among variables but CATPCA optimally quantifies variables in the specified dimension helps in modeling nonlinear relationships among variables [24,25]. In CATPCA, model estimation and optimal quantification are alternated through use of an iterative algorithm that converges to a stationary point where the optimal quantifications of the categories do not change further.

\section{Objectives}

The objective of the current study is to assess the spatial patterns of landscape changes in the forested district (Uttara Kannada district) of Central Western Ghats in Karnataka. This involves,

- Temporal analysis of LULC changes considering RS data;

- Analyses of the spatial patterns of landscape changes through spatial metrics at temporal scale to define relationships between land use and landscape structure; and

- Prioritization of regions through visualization of spatial patterns of landscape dynamics.

\section{Materials and Methods}

\section{Study area}

Uttara Kannada district in Karnataka State, India (Figure 1) is blessed with highest forest cover (among all districts in India), perennial streams and productive estuaries. The district has a tropical climate with the mean annual rainfall of $4237 \mathrm{~mm}$ and elevation ranges from 0 to $1050 \mathrm{~m}$ (above Sea level). The district has $140 \mathrm{~km}$ coastal line and surrounded by Belgaum district, Goa state in North, Shimoga and Udupi districts in the South, Dharwad district in the East, Arabian Sea forms the West border. The west flowing rivers (Kali, Bedthi, Aganashini, Sharavathi, Venkatapur) break the shoreline of Uttara Kannada by deep and wide mouthed estuaries, larger creeks with ample biodiversity. The district forms three distinct agro climatic zones covering 11 taluks (local administrative division) due to its varied topography, i.e., coast, hilly or Sahyadri Interior and plains. The total population of the district is 1502454 (as per 2011 census) with 146 persons per sq.km density. The costal and plains are expressing higher population presence compared to the undulating hilly taluks. The forests are stimulated by heavy rainfall, start growing within a few kilometers from the coast with lofty, dense canopies of tree crowns and shrub growth. As one moves from coast to Ghats (Sahyadri Interior), the forests are semi-evergreen to evergreen with grassy banks. Forest ecosystems in Uttara Kannada district have witnessed major transformations during the past four decades. Implementation of developmental activities without taking into account the ecological significance and services provided by them in meeting the livelihood of local population has resulted in the degradation of forests through large scale land use changes.

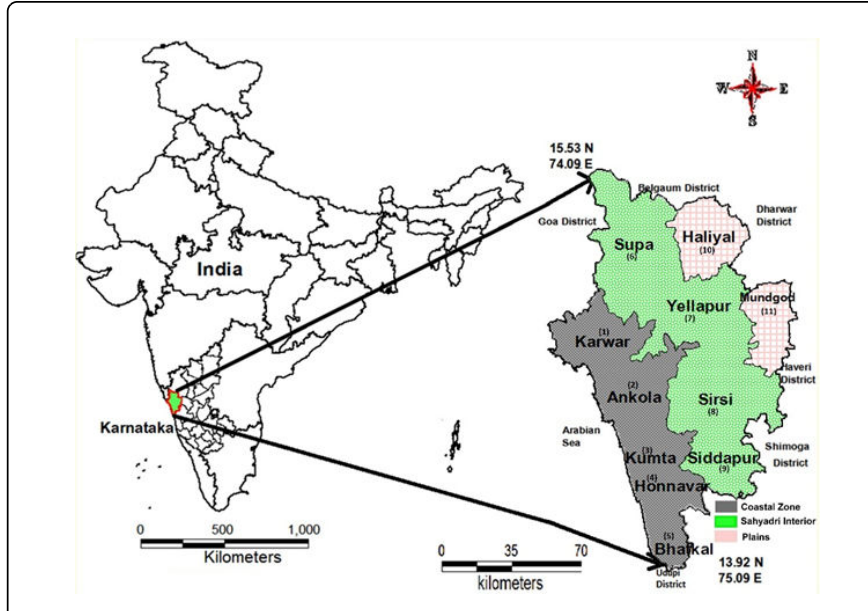

Figure 1: Study area-Uttara Kannada district, India.

\section{Data}

Land cover change elucidation relies on an accurate interpretation of baseline conditions and changes in the surface spectral properties over time. LULC dynamics of Uttara Kannada district have been analyzed using temporal Landsat series RS data (1973-2016) with ancillary data and field data as given in Figure 2. Ancillary data include cadastral revenue maps (1:6000), the Survey of India (SOI) topographic maps (1:50000 and 1:250000), vegetation map (1:250000) of South India developed by French Institute (1986). Digitized topographic maps helped in the extraction of ground control points (GCP's) to rectify RS data. Vegetation map of South India (1986) of scale 1:250000 [26] was useful in identifying various forest cover types during 1980's, required for classifying 1980's RS data. Other ancillary data includes land cover maps, administration boundary data, transportation data (road network), etc. Pre-calibrated GPS (Garmin GPS unit) were used for field data collection and used in georeferencing, classifying RS data as well as validation. The Landsat data of 1973 with a spatial resolution of $57.5 \mathrm{~m} \times 57.5 \mathrm{~m}$ (nominal resolution) were resampled to $30 \mathrm{~m}$ (nominal resolution) to maintain the uniform resolution across different time (1989-2016) data. Landsat ETM+ bands of 2013 were corrected for the SLC-off through image enhancement and restoration techniques, followed by nearestneighbor interpolation.

Land cover analysis essentially involves delineating the region under vegetation and non-vegetation, which is done through the computation of vegetation indices NDVI (Normalized Difference Vegetation Index), given in equation 1 . Among all techniques of land cover mapping through NDVI is most widely accepted and being applied [21,27], which ranges from +1 to -1 . Very low values of NDVI ( -0.1 and below) correspond to non-vegetation (soil, barren areas of rock, sand, built up, etc.) and NDVI of zero corresponds to water bodies. Moderate values represent low density vegetation ( 0.1 to 0.3 ), while high values indicate thick canopy vegetation (0.6 to 0.9 ). The outcome of NDVI (for the latest time period) was verified through field investigation.

$$
N D V I=\frac{N I R-R}{N I R+R}
$$


Page 3 of 8

Land use analyses involved (i) generation of False Color Composite (FCC) of RS data (bands-green, red and NIR). This composite image helps in locating heterogeneous patches in the landscape, (ii) selection of training polygons by covering $15 \%$ of the study area (polygons are uniformly distributed over the entire study area) (iii) loading these training polygons co-ordinates into pre-calibrated GPS, (vi) collection of the corresponding attribute data (land use types) for these polygons from the field, (iv) supplementing this information with Google Earth and (v) $60 \%$ of the training data has been used for classification based on Gaussian Maximum Likelihood algorithm, while the balance is used for validation or accuracy assessment (ACA). The land use analysis was done using supervised classification technique based on Gaussian maximum likelihood algorithm with training data. The land use is classified under 11 categories such as Built-up (B), Water (W), Crop land (C), Open fields (O), Moist deciduous forest (MD), Evergreen to semi evergreen forest (ES), Scrub/grass (SG), Acacia/ Eucalyptus/Hardwood plantations (HP), Teak/Bamboo/Softwood plantations (SP), Coconut/Areca nut/Cashew nut plantations (CP), Dry deciduous forest (DD). GRASS GIS (Geographical Resources Analysis Support System, http://ces.iisc.ernet.in/grass)-free and open source software has been used for analyzing RS data by using available multi-temporal "ground truth" information. Earlier time data were classified using the training polygon along with attribute details compiled from the historical published topographic maps, vegetation maps, revenue maps, land records available from local administrative authorities.

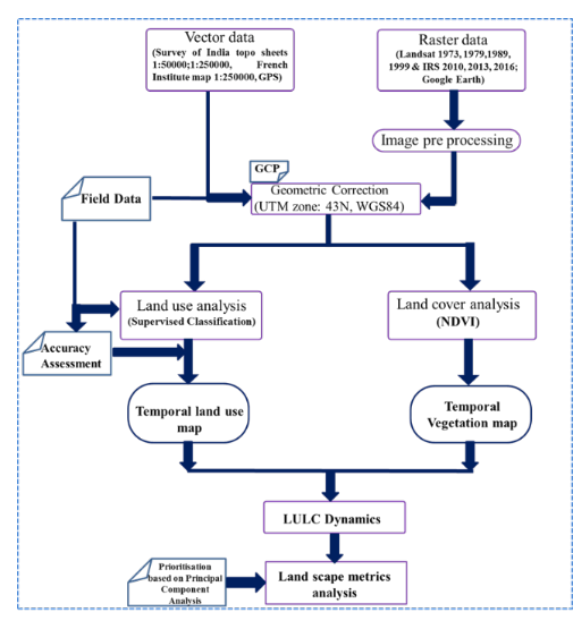

Figure 2: Method followed in the study.

ACA is done through error matrix (also referred as confusion matrix), and computation of kappa ( $\kappa$ ) statistics, overall (producer's and user's) accuracies to evaluate the quality of the information derived from remotely sensed data considering training data. Kappa statistic compares two or more matrices and weighs cells in error matrix according to the magnitude of misclassification [28-30]. LU change rate for each category are computed by considering respective land use spatial extent in two time periods. The annual rate of change is computed using equation 2 to identify magnitude of changes in the respective land use category [31-33]. This approach helps to determine change rates from "known cover" as observed forest cover by providing areas that had changed to non-forest [34]. This computation is based on the area that was classified as forest in the first date and changed to non-forest in the second date.
Change rate $=\left(\frac{\ln \left(A_{t 1}\right)-\ln \left(A_{t 0}\right)}{\left(t_{1}-t_{0}\right)}\right) \times 100$

Where $A_{t 1}$ is area of land use class in current year, $A_{t 0}$ is area of class in base year, $t_{1}$ is current year, $t_{0}$ is base year and $L n$ is natural logarithm. The equation will result \% change of each land use class with negate and positive. The negative changes indicate to rate of loss; whereas positive change rate indicate gain in land use class.

Spatial patterns of landscape dynamics are assessed through prioritised [3,35-40] spatial metrics computed using Fragstats 3.3 [16]. Prioritised indices such as Class area (CA) has provided temporal change in forest area over non-forest cover in the landscape. Number of patches (NP) is a fragmentation based indices to account forest status, as less NP value represents intact forest and greater values results more fragmented patches. PAFRAC (Perimeter-Area Fractal Dimension) index indicates forest patch perimeter, stating either simple (homogeneous aggregation or intact forest present) or complex (the fragment that are being formed by intrusion). Patch indices (such as LPI- largest patch index) is computed to understand the process of deforestation as it provides larger patch in the landscape. Edge density (ED) analyses whether the region has simple edges or complex due to fragmentation. AREA_MN illustrates mean of forest area representing higher mean as more aggregation and vice versa. Shape metrics such as Landscape Shape Index (LSI), NLSI (Normalized Landscape Shape Index), Mean shape index (SHAPE_MN) and Mean patch fractal dimension (FRAC_MN) explain shape complexity and dynamic pattern of land use. Mean Euclidean nearest neighbour distance (ENN_MN) provides the information of disturbance regimes, as intermediate patches such as developments, clearing of forest patches lead to increase in nearest neighbour distance of forest patches. Clumpy Index shows clumped/aggregation of forest patches in the landscape, Aggregation index (AI) refer to specific forest class aggregation and is independent of landscape composition. Interspersion and Juxtaposition (IJI) is a measure of patch adjacency, values will decrease due to increase in the neighbouring forest patch distance in all the directions. CATPCA is the nonlinear PCA used to reduce the observed variables to a number of uncorrelated principal components by using student copy of IBM SPSS version 20 .

\section{Results and Discussion}

Spatio temporal Landscape dynamics the spatial extent of temporal vegetation computed through NDVI reveals a decline of vegetation from $97.82 \%$ (1973) to $80.42 \%$ (2016). Areas under non-vegetation have increased (Figure 3) to $19.58 \%$ (2016) from 2.18\% (1973), due to anthropogenic activities (Figure 4). Comparative assessment of land use categories reveals the decline of vegetation cover in the district (Table 1) during 1973 to 2016, Figure 5). The reduction of area under evergreen forests from $67.73 \%$ (1973) to $29.5 \%$ (2016) due to anthropogenic activities. Transition of evergreen-semi evergreen forests to moist deciduous forests, and some have been converted into plantations (such as Acacia auriculiformis, Casuarina equisetifolia, Eucalyptus spp., and Tectona grandis etc.) constitute $10.78 \%$ and $7.67 \%$ respectively. Enhanced agricultural activities is evident from the increase of agricultural land use from 7 (1973) to $14.3 \%$ (2016) and the area under human habitations have increased during the last four decades, evident from the increase of built-up area from $0.38 \%$ (1973) to $4.97 \%$ (2016). The dry deciduous forest cover is very less $(1.27 \%)$ and is found mainly in the north eastern part of the district in Mundgod taluk and partly Haliyal taluk. 
Citation: Ramachandra TV, Bharath S (2018) Geoinformatics based Valuation of Forest Landscape Dynamics in Central Western Ghats, India. J Remote Sensing \& GIS 7: 227. doi:10.4172/2469-4134.1000227
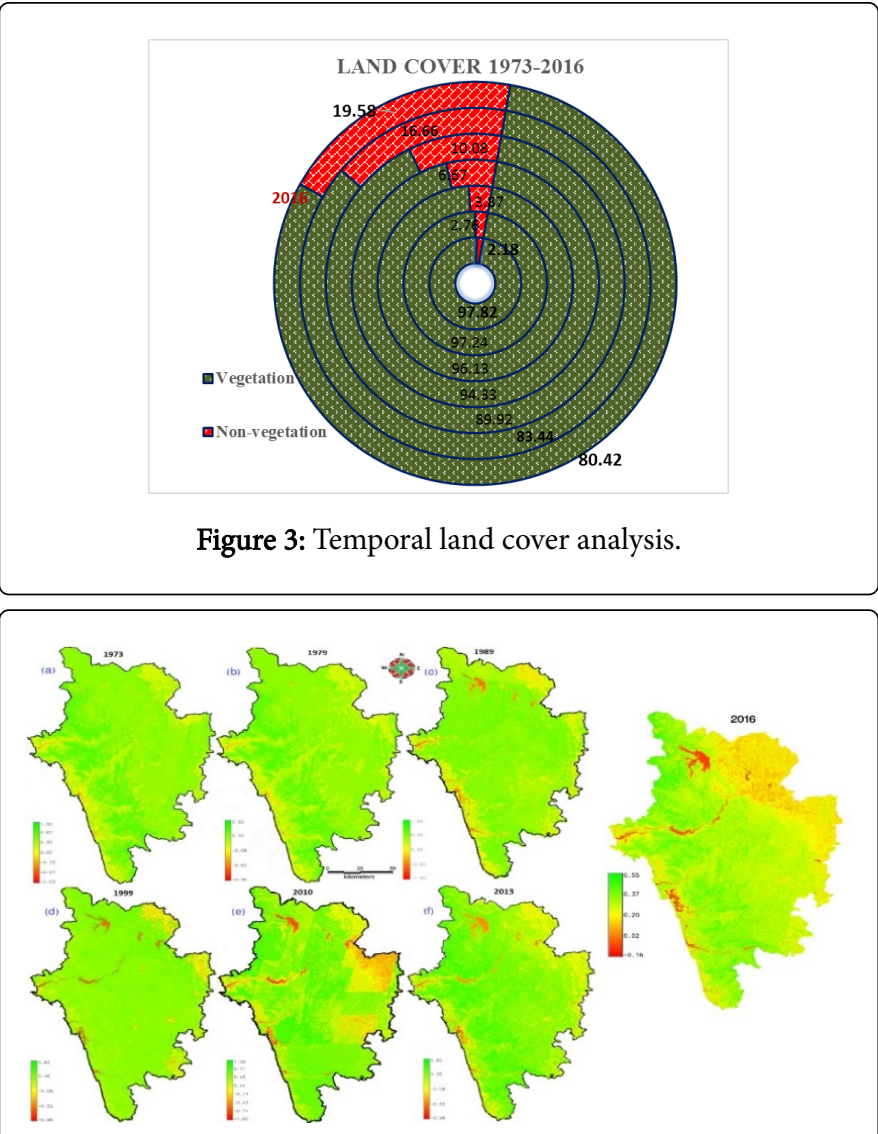

Figure 4: Land cover analysis from 1973 to 2016.

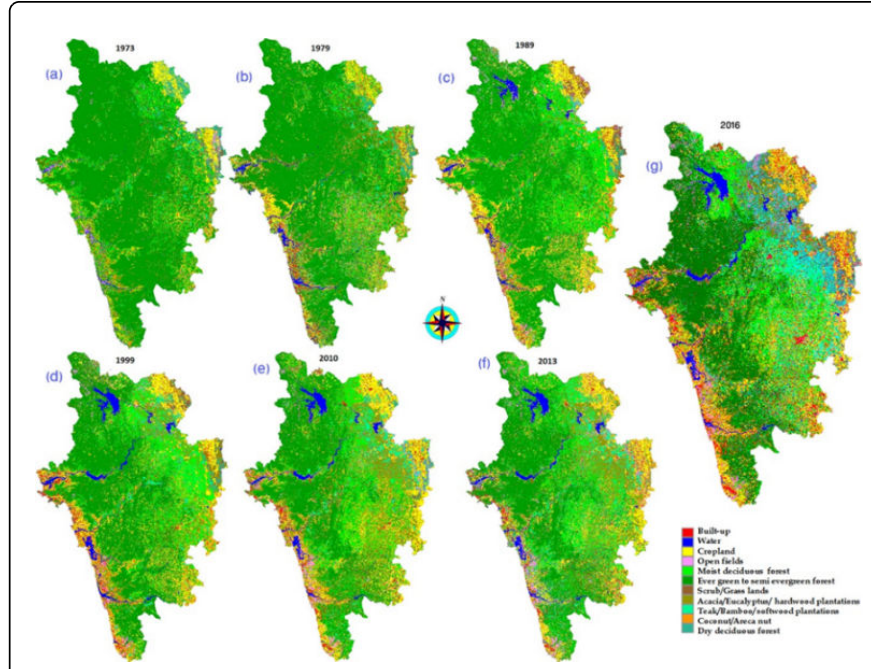

Figure 5: Uttara Kannada district land use change from 1973 to 2016.

Unplanned developmental activities coupled with the enhanced agriculture and horticultural activities have aided as prime drivers of deforestation, leading to the irreversible loss of forest cover with the reduction of ecosystem goods and services. The ACA (Table 2), verified using field data and Google earth data shows an accuracy of $82-92 \%$ with consistent results. Cautious steps were taken to make sure separate data sets used for training and validation to attain greater accuracy by consistent classification and confirmation. Category-wise land use change rates were computed; higher changes are noticed during 1973-79 followed by 2010 to 2016 (Figure 6).

\begin{tabular}{|l|l|l|l|l|l|l|l|l|}
\hline Year ? Category (Ha) & $\mathbf{1 9 7 3}$ & $\mathbf{1 9 7 9}$ & $\mathbf{1 9 8 9}$ & $\mathbf{1 9 9 9}$ & $\mathbf{2 0 1 0}$ & $\mathbf{2 0 1 3}$ & $\mathbf{2 0 1 6}$ & $\begin{array}{l}\text { Loss/Gain } \\
\mathbf{( 1 9 7 3 - 2 0 1 6 )}\end{array}$ \\
\hline B & 3886 & 9738 & 12982 & 21635 & 28491 & 31589 & 51132 & 47246 \\
\hline W & 7681 & 18527 & 16604 & 32983 & 26119 & 28113 & 28228 & 20547 \\
\hline C & 71990 & 103163 & 121167 & 138458 & 148187 & 145395 & 147109 & 75119 \\
\hline O & 14071 & 15988 & 34783 & 21945 & 30813 & 37660 & 42634 & 28563 \\
\hline MD & 95357 & 102967 & 143849 & 179075 & 166266 & 161996 & 164239 & 68882 \\
\hline ES & 696978 & 589762 & 531872 & 423062 & 367064 & 330204 & 303585 & -393393 \\
\hline SG & 38109 & 58936 & 44123 & 47366 & 35158 & 40402 & 42083 & 3974 \\
\hline HP & 40905 & 50321 & 55694 & 73977 & 119717 & 122927 & 110950 & 70045 \\
\hline SP & 13997 & 20896 & 21937 & 38588 & 44794 & 67111 & 78953 & 64956 \\
\hline CP & 20702 & 29675 & 32227 & 43623 & 53646 & 53993 & 47135 & 26433 \\
\hline DD & 25410 & 29113 & 13848 & 8374 & 9008 & 9873 & 13038 & -12372 \\
\hline Total Area & & & & & 1029086 & & \\
\hline
\end{tabular}

Table 1: Spatio temporal land use changes during 1973 to 2016. 
Page 5 of 8

Non-forest regions such as agriculture, built environments show an increasing trend in each time period. The built-up area shows a positive increase of $15.31 \% \mathrm{y}^{-1}$ (per year). The evergreen forest shows change of $-2.78 \% \mathrm{y}^{-1}$ (1973-1979) and $-2.80 \% \mathrm{y}^{-1}$ (2013-2016). The grater loss of evergreen forests can be seen as 3.53\% $\mathrm{y}^{-1}(2010-2013)$ due to major motor ways expansion. Forest plantations and horticulture show an increase during 1973 to 2016, indicating market's role in land conversion. The abrupt land use changes are due to largescale developmental activities, increased agriculture to meet the growing demand of population.

\begin{tabular}{|l|l|l|}
\hline Year & Overall Accuracy & Kappa \\
\hline 1973 & 82.52 & 0.81 \\
\hline 1979 & 84.29 & 0.81 \\
\hline 1989 & 92.22 & 0.89 \\
\hline 1999 & 90.71 & 0.87 \\
\hline 2010 & 91.51 & 0.89 \\
\hline 2013 & 91.98 & 0.90 \\
\hline 2016 & 90.0 & 0.88 \\
\hline
\end{tabular}

Table 2: ACA of the study. Here, PA Producer's Accuracy and UA User's Accuracy.

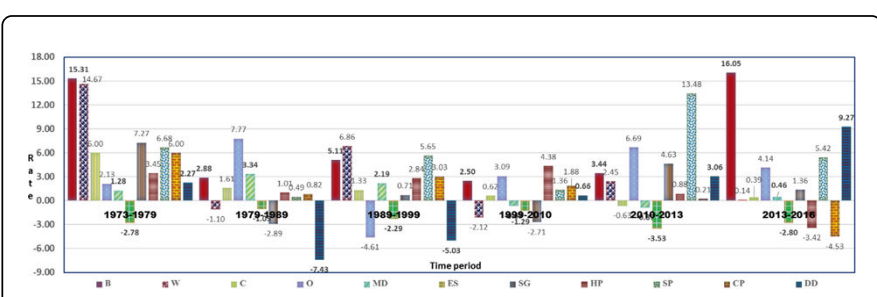

Figure 6: Temporal variation of land use change rate from 1973 to 2016.

\section{Spatial metrics analysis and landscape prioritization}

Spatial metrics were computed to quantify spatial patterns among three diverse landscapes at class level over time. The analysis of spatial metrics representing area, edge/border, compactness/dispersion, shape categories provided an overall summary of landscape composition and configuration over a period of four decades. CATPCA was carried out with relative weights of spatial metrics that provided vital insights to the spatial patterns of landscape. CATPCA considering 1973 and 2016 metrics data retained all components that were significant and the resulting components that are the major independent dimensions
(Table 3) shows the combination of the categories. The two dimensions together explained $74.49 \%$ cumulative variance with eigenvalues of 7.98 (Dimension-1), 3.196 (Dimension-2) in 1973. The Dimension-1 has significantly positive correlation with SHAPE_MN, FRAC_MN, PAFRAC, NLSI, CA representing shape complexity property and negatively with CLUMPY, AI. The Dimension-2 represents NP, ED as positive and AREA_MN, LPI are showing negative correlation for the year 1973. Figure 7a shows taluks 1, 3, 4, 5, 9 and 10 representing forested regions (corresponding to major taluks of three agro-climatic regions) in 1973 form a single cluster with simple shapes and least number of patches. Taluks 7 and 2 form a cluster with higher influence of LPI and IJI indicating the presence of largest forest patches in these regions. Sirsi (8) taluk show higher fragmentation evident from NP, ED and large number of edges in the peripheral forested patches. CATPCA analysis for 2016 depicts cumulative variance of $69.14 \%$ under two dimensions with eigenvalues of 5.7 and 4.7 respectively. Figure $7 \mathrm{~b}$ shows response variables exhibited a range of behaviours with respect to different levels of class proportion at temporal scale. In Dimension 1, NP, LPI, ED, LSI, SHAPE_MN are positively correlated and PARA_MN, CLUMPY, AI are negatively correlated. Dimension-2 represents CA, AREA_MN as positive and ENN_MN, NLSI represents negative correlation depicting the property of disaggregation of forest patches.

As class proportion of forest cover has decreased, there is a large increase in the standardized CLUMPY and aggregation indices, which lead to form a single cluster for all coastal taluks with similar spatial patterns of changes (coastal taluks 1, 2, 3, 4 and partly 5). The Sahyadri Interior region show intra spatial heterogeneity highlighted by CA, IJI. The high forested taluk Supa (6) has not expressing any influence of shape and patch metrics. Taluk 7 has major influence of SHAPE_MN, ED represents the irregular forest shape by alternation with the increase of non-forest activities. Taluks 8 had major influence of NP, LSI and PAFRAC depicting their shape irregularity followed by fragmentation. The development of new individual non-forest patches, as reflected by the slightly increases in NP and LSI resulted in more complicated patch shapes in the meantime, also produced many smaller and isolated fragmented patches at a temporal scale. Plains (taluks 10,11) cluster shows influence of ENN_MN, NLSI as increase of nearest neighbour of forest patch with decrease of mean area cover indicating the region is losing its forest cover abruptly at temporal scale with increase in shape complexity. ED indicates that all taluks representing simple edges (almost square) in 1973 and transform to complex with convoluted edges in all directions in 2016 due to fragmentation with newly developing edges. The landscapes of three agro climatic zones differ in several ways, most clearly in their proportion of forest cover and spatial heterogeneity by 2016 . Landscape metrics aided in quantifying the spatial patterns among three distinct and diverse landscapes. This approach has provided context for interpretable set of landscape patterns that objectively represent temporal land use changes in each forested taluk.

\begin{tabular}{|l|l|l|l|l|l|}
\hline \multicolumn{7}{|c|}{ Component loadings (1973 and 2016) } \\
\hline \multirow{2}{*}{ SNO } & \multirow{2}{*}{ Spatial metrics } & Dimension (1973) & $\mathbf{1}$ & $\mathbf{2}$ & \multicolumn{2}{l|}{ Dimension (2016) } \\
\cline { 3 - 7 } & CA & 0.649 & -0.688 & $\mathbf{1}$ & $\mathbf{2}$ \\
\hline 2 & NP & 0.370 & 0.743 & 0.35 & 0.806 \\
\hline
\end{tabular}


Citation: Ramachandra TV, Bharath S (2018) Geoinformatics based Valuation of Forest Landscape Dynamics in Central Western Ghats, India. J Remote Sensing \& GIS 7: 227. doi:10.4172/2469-4134.1000227

Page 6 of 8

\begin{tabular}{|c|c|c|c|c|c|}
\hline 3 & LPI & -0.228 & -0.634 & 0.767 & 0.556 \\
\hline 4 & ED & 0.633 & 0.676 & 0.801 & 0.072 \\
\hline 5 & LSI & 0.991 & -0.113 & 0.764 & -0.348 \\
\hline 6 & AREA_MN & -0.044 & -0.762 & 0.187 & 0.86 \\
\hline 7 & SHAPE_MN & 0.986 & -0.146 & 0.907 & 0.009 \\
\hline 8 & FRAC_MN & 0.986 & -0.146 & 0.618 & -0.106 \\
\hline 9 & PARA_MN & -0.272 & 0.165 & -0.783 & -0.099 \\
\hline 10 & PAFRAC & 0.986 & -0.146 & 0.701 & -0.201 \\
\hline 11 & ENN_MN & -0.352 & 0.306 & -0.35 & -0.806 \\
\hline 12 & CLUMPY & -0.986 & 0.146 & -0.543 & 0.551 \\
\hline 13 & $|\mathrm{~J}|$ & -0.349 & -0.581 & -0.013 & 0.942 \\
\hline 14 & $\mathrm{Al}$ & -0.896 & -0.391 & -0.558 & 0.633 \\
\hline 15 & NLSI & 0.986 & -0.146 & -0.291 & -0.598 \\
\hline \multicolumn{6}{|c|}{ Variance accounted for each time period } \\
\hline \multirow{2}{*}{\multicolumn{2}{|c|}{ Dimension }} & \multicolumn{2}{|l|}{1973} & \multicolumn{2}{|l|}{2016} \\
\hline & & Total (Eigenvalue) & $\%$ of Variance & Total (Eigenvalue) & $\%$ of Variance \\
\hline \multicolumn{2}{|l|}{1} & 7.979 & 53.192 & 5.7 & 38.07 \\
\hline \multicolumn{2}{|l|}{2} & 3.196 & 21.306 & 4.7 & 31.07 \\
\hline \multicolumn{2}{|c|}{ Total } & 11.175 & 74.498 & 10.4 & 69.14 \\
\hline
\end{tabular}

Table 3: Component loadings of CATPCA among two dimensions and variance accounted.

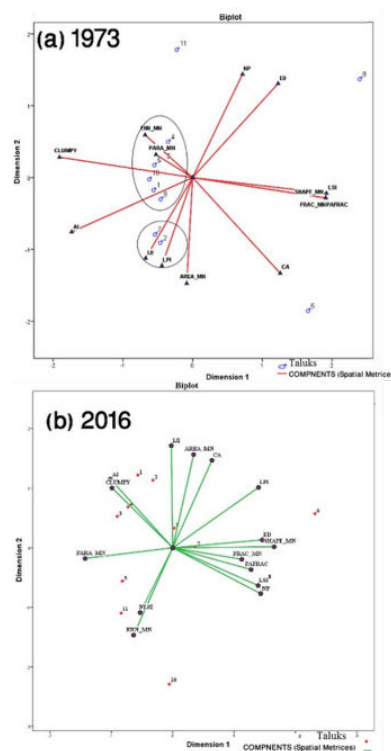

Figure 7: Spatial patterns of (a)1973 and (b) 2016.

\section{Conclusion}

Analysis of LULC dynamics using temporal RS data aided in understanding causes of changes, focussing on conservation and restoration of ecosystems. The LULC analyses of Uttara Kannada during 1973 to 2016 show significant variation during the last four decades as evergreen forests have declined from $67.73 \%$ (1973) to $29.5 \%$ (2016) and area under human habitations and paved surfaces have reached $4.97 \%$ (2016). Decline in forest cover in Costal taluks is due to housing, agriculture, transportation, etc. Sirsi, Siddapur, Haliyal, Yellapur and Mundgod regions have experienced changes in forest cover due to encroachments by disturbing local ecology. Market based economy has motivated Honnavara, Siddapur regions conversion of land for commercial crops. Landscape metrics helped in understanding spatial patterns of landscape, similar configurations and variation across the forested area of Uttara Kannada for devising appropriate effective management and decision making towards the sustainable development. Spatial metrics depicts the whole landscape in 1973 represents a simple spatial pattern except Mundgod and Sirsi. In 2016, due to continued changes in the structure by deforestation, the three agro climate regions are represented by dissimilar patterns. The costal taluks are more fragmented towards west (higher NP) and plain taluks expressing higher nearest neighbor distance (ENN_MN) of forest patches as shown by due to intermediate by exotic plantations. Edge effects have a rapidly increasing impact on Sahyadri Interior taluks forest dynamics in lower elevations and Sirsi taluk has higher 
NP due to more intermediate patches of non-forest types. CATPCA along with spatial metric clustering information visually demonstrated the ability of these metrics to express the variation of patterns at the landscape scale. Variation in landscape spatial heterogeneity/similarity has provided regional level picture of the district, which can be used to frame conservation policies to protect social and ecological sustainability of ecosystems.

\section{Acknowledgements}

We acknowledge the sustained financial support for ecological research in Western Ghats from (i) NRDMS division, The Ministry of Science and Technology (DST), Government of India, (ii) Indian institute of Science and (iii) ENVIS division, The Ministry of Environments, Forests and Climate Change, Government of India. We thank Vishnu Mukri and Srikanth Naik for the assistance during field data collection.

\section{References}

1. Forman RTT, Godron M (1986) Landscape Ecology. Willey, New York, USA.

2. Lambin EF, Geist H, Lepers E (2003) Dynamics of land use and land cover change in tropical regions. Environment and Resources 28: 205-241.

3. Ramachandra TV, Bharath S, Bharath HA (2012) Peri-Urban to Urban Landscape Patterns Elucidation through Spatial Metrics. International Journal of Engineering Research and Development 2: 58-81.

4. Ramachandra TV, Bharath S, Nimish G (2018) Modelling landscape dynamics with LST in protected areas of Western Ghats, Karnataka. Journal of Environmental Management 206: 1253-1262.

5. Dupont L, Van EV (2013) Assessing the potential impacts of climate change on traditional landscapes and their heritage values on the local level: Case studies in the Dender basin in Flanders, Belgium. Land Use Policy 35: 179-191.

6. Bharath S, Rajan KS, Ramachandra TV (2013) Land Surface Temperature Responses to Land Use Land Cover Dynamics. Geoinfor Geostat An Overview 1: 4.

7. Ramachandra TV, Shruthi BV (2007) Spatial mapping of renewable energy potential. Renewable and Sustainable Energy Reviews 11: 1460-1480.

8. Kindu M, Schneider T, Teketay D, Knoke T (2016) Changes of ecosystem service values in response to land use/land cover dynamics in MunessaShashemene landscape of the Ethiopian highlands. Science of the Total Environment 547: 137-147.

9. Bharath S, Nimish G, Ramachandra TV (2017) Visualization and Prediction of Landscape Dynamics in The Protected Areas of Karnataka. International Journal of Research in Engineering and Technology 6: 53-62.

10. Simon B, Che E, Robert H, Adrienne G (2012) Assessing the impacts of economic and climate changes on land-use in mountain regions: A spatial dynamic modeling approach. Agriculture Ecosystems \& Environment 149: 50-63.

11. Geneletti D (2015) A conceptual approach to promote the integration of ecosystem services in strategic environmental assessment. Journal of Environmental Assessment Policy and Management 17: 1-27.

12. Smiraglia D, Ceccarelli T, Bajocco S, Salvati L, Perini L (2016) Linking trajectories of land change, land degradation processes and ecosystem services. Environmental Research 147: 590-600.

13. Vinay S, Bharath S, Bharath HA, Ramachandra TV (2013) Hydrologic model with landscape dynamics for drought monitoring. Proceeding of Joint International Workshop of ISPRS WG VIII/1 and WG IV/4 on Geospatial Data for Disaster and Risk Reduction, Hyderabad, India, pp: 21-22.
14. Zhou W, Troy A, Grove M (2008) Modeling residential lawn fertilization practices: Integrating high resolution remote sensing with socioeconomic data. Environmental Management 41: 742-752.

15. Svoray T, Avi P, Atkinson PM (2013) Ecological sustainability in rangelands: the contribution of remote sensing. International Journal of Remote Sensing 34: 6216-6242.

16. McGarigal K, Marks BJ (1995) FRAGSTATS: Spatial pattern analysis program for quantifying landscape structure. Gen Tech Report PNWGTR-351, USDA Forest Service, Pacific Northwest Research Station, Portland, Oregon, USA.

17. Herold M, Couclelis H, Clarke KC (2005) The role of spatial metrics in the analysis and modeling of urban land use change. Computers, Environment and Urban Systems 29: 369-399.

18. Uuemaa E, Antrop M, Roosaare J, Marja R, Mander U (2009) Landscape Metrics and Indices: An Overview of Their Use in Landscape Research. Living Reviews in Landscape Research 3: 1-28.

19. Bhattarai K, Conway D, Mahmoud Y (2009) Determinants of deforestation in Nepal's central development region. Journal of Environmental Management 91: 471-488.

20. Jiao L, Liu Y, Li H (2012) Characterizing land-use classes in remote sensing imagery by shape metrics. ISPRS Journal of Photogrammetry and Remote Sensing 72: 46-55.

21. Ramachandra TV, Bharath S, Bharath AH (2014) Spatio-temporal dynamics along the terrain gradient of diverse landscape. Journal of Environmental Engineering and Landscape Management 22: 50-63.

22. Jackson DA (1993) Stopping rules in principal components analysis: a comparison of heuristical and statistical approaches. Ecology 74: 2204-2214.

23. Samuel AC, McGarigal K, Neel MC (2008) Parsimony in landscape metrics: Strength, universality, and consistency. Ecological Indicators 8: 691-703.

24. Meulman JJ, Heiser WJ (2004) SPPS, SPSS Categories 13.0. Chicago, USA.

25. Linting M, Meulman JJ, Groenen PJ, van der Koojj AJ (2007) Nonlinear principal components analysis: introduction and application. Psychological methods 12: 336-358.

26. Pascal JP (1986) Explanatory booklet on the forest map of South India. French Institute, Pondicherry, India 3: 19-30.

27. Nelson RF (1983) Detecting forest canopy change due to insect activity using Landsat MSS. Photogrammetric Engineering \& Remote Sensing 49: 1303-1314.

28. Lillesand T, Kiefer RW, Chipman J (2014) Remote sensing and image interpretation. John Wiley \& Sons, New Jersey, USA.

29. Kennedy RE, Townsend PA, Gross JE, Cohen WB, Bolstad P, et al. (2009) Remote sensing change detection tools for natural resource managers: understanding concepts and tradeoffs in the design of landscape monitoring projects. Remote Sensing of Environment 113: 1382-1396.

30. Liu C, Frazier P, Kumar L (2007) Comparative assessment of the measures of thematic classification accuracy. Remote Sensing of Environment 107: 606-616.

31. FAO (1995) Forest resources assessment 1990: Global Synthesis. Rome.

32. Puyravaud JP (2003) Standardizing the evaluation of the annual rate of deforestation. Forest Ecology Management 177: 593-596.

33. Armenteras D, Rudas G, Rodriguez N, Sua S, Romero M (2006) Patterns and causes of deforestation in the Colombian Amazon. Ecological Indicators 6: 353-368.

34. Riitters KH, O'Neill RV, Hunsaker CT, Wickham JD, Yankee DH, et al. (1995) A factor analysis of landscape pattern and structure metrics. Landscape Ecology 10: 23-39.

35. Echeverria C, David AC, Hall M, Newton AC (2008) Spatially explicit models to analyze forest loss and fragmentation between 1976 and 2020 in southern Chile. Ecological Modelling 212: 439-449.

36. Tabor K, Burgess ND, Mbilinyi BP, Kashaigili JJ, Steininger MK (2010) Forest and woodland cover and change in coastal Tanzania and Kenya, 1990 to 2000. Journal of East African Natural History 99: 19-45. 
Citation: Ramachandra TV, Bharath S (2018) Geoinformatics based Valuation of Forest Landscape Dynamics in Central Western Ghats, India. J Remote Sensing \& GIS 7: 227. doi:10.4172/2469-4134.1000227

Page 8 of 8

37. Setturu B, Bharath HA, Sanna Durgappa D, Ramachandra TV (2012) Landscape dynamics through spatial metrics. Proceedings of India GeoSpatial Conference, Epicentre, Gurgaon, India.

38. Plexida SG, Sfougaris AI, Ispikoudis IP, Papanastasis VP (2014) Selecting landscape metrics as indicators of spatial heterogeneity-A comparison among Greek landscapes. International Journal of Applied Earth Observation and Geoinformation 26: 26-35.
39. Singh SK, Srivastava PK, Szabó S, Petropoulos GP, Gupta M, et al. (2017) Landscape transform and spatial metrics for mapping spatiotemporal land cover dynamics using Earth Observation data-sets. Geocarto International 32: 113-27.

40. Turner MG, Simard M (2017) Using Spatial Statistics and Landscape Metrics to Compare Disturbance Mosaics. In: Learning Landscape Ecology. Springer, New York, USA, pp: 175-190. 